\title{
Diagnóstico de uma área compactada por atividade minerária, na floresta amazônica, empregando métodos geoestatísticos à variável resistência mecânica à penetração do solo ${ }^{1}$
}

\begin{abstract}
Admilson Írio RIBEIRO ${ }^{2}$, Regina Márcia LONGO $^{3}$, Aristóteles TEIXEIRA FILHO ${ }^{4}$, Wanderley José de MELO $^{5}$

\section{RESUMO}

O processo de mineração provoca uma desfiguração do terreno e uma completa alteração da paisagem. Um problema bastante comum na revegetação de áreas degradadas na exploração mineral compreende a compactação do solo/substrato devido ao intenso tráfego de máquinas e movimentação de terra. Os problemas mais comuns da compactação de uma superfície degradada são: aumento da resistência mecânica à penetração radicular, redução da aeração, alteração do fluxo de água e calor, comprometendo a disponibilidade de água e nutrientes do local. Sendo assim, o presente trabalho teve como objetivo básico diagnosticar, de forma espacial, a compactação de uma área minerada por meio da resistência mecânica à penetração. O diagnóstico da área compactada foi efetuado para orientar uma futura subsolagem no local visando posterior revegetação. Através dos estudos, concluiu-se que o método de interpolação (krigagem), de acordo com a variação espacial da resistência mecânica à penetração, permite dividir a área estuda em subáreas possibilitando um futuro gerenciamento localizado de forma a reduzir custos e interferências desnecessárias ao ambiente. O método mostrou-se bastante eficiente e pode ser utilizado em diagnóstico da compactação em áreas mineradas, prevendo necessidade de subsolagem.
\end{abstract}

\section{PALAVRAS-CHAVE}

compactação; krigagem; variabilidade espacial

\section{Diagnosis of a compacted area by mining activity, in the Amazon forest, utilizing geoestatistic methods to the mechanical resistence variable to the penetration of the soil}

\begin{abstract}
A quite common problem in the recovery of degraded areas in the mineral exploration understands the compaction of the soil due to the intense traffic of machines and earth movement. The most common problem of the compaction of a degraded surface is: increase of the mechanical resistance to the penetration of the rooats, reduction of the aeration, alteration of the water flow and heat. Thus the present work had the basic objective of diagnosing the compaction of a degraded area by mining in a space way, through the mechanical resistance the way penetration to guide a future subsoiling in the place seeking recovery. Through the studies it was concluded that the kriging method in agreement with the space variation allows the division of the area studies in sub areas facilitating a future work to reduce cost and unnecessary interference to the atmosphere. The method was shown quite appropriate and it can be used in diagnosis of the compaction in a degraded area by mining, foreseeing subsoiling need.
\end{abstract}

\section{KEYWORDS}

compaction; kriging; space variability

\footnotetext{
${ }^{1}$ Parte do projeto temático financiado pela FAPESP

${ }^{2}$ Eng. Agrícola/Doutorando pela FEAGRI/UNICAMP Estr. da Rhodia, 5555 cs 91 B. Geraldo-Campinas/SP. E-mail: admilson@agr.unicamp.br

${ }^{3}$ Eng. Agrônoma/Pós-doutarada UNESP/Jaboticabal

${ }^{4}$ Eng. Agrônomo/Doutorando pela FEAGRI/UNICAMP

${ }^{5}$ Prof. Titular/UNESP/Jaboticabal
} 


\section{ACTA \\ AMAZONICA}

DIAGNÓSTICO DE UMA ÁREA COMPACTADA POR ATIVIDADE MINERARIA, NA FLORESTA AMAZÔNICA,EMPREGANDO MÉTODOS GEOESTATÍSTICOS À VARIÁVEL RESISTÊNCIA MECÂNICA À PENETRAÇÃO DO SOLO

\section{INTRODUÇÃO}

Atualmente a mineração ou exploração mineral é uma atividade indispensável para a sociedade moderna, dada a importância que os bens minerais e derivados assumiram na economia mundial que, de uma forma geral, vão desde as necessidades básicas como habitação, agricultura, transporte e saneamento, às mais sofisticadas, como tecnologia de ponta nas áreas de comunicação e informática.

De uma forma geral, o ecossistema que sofreu alterações proporcionando a perda da cobertura vegetal e os meios de regeneração bióticos (banco de sementes e de plântulas e rebrota) é segundo Carpanezzi et al. (1990), um ecossistema degradado. Para Lal \& Stewart (1992), a degradação do solo implica na redução da sua capacidade produtiva, resultante do uso intensivo, causando mudanças e promovendo alteração nas propriedades físicas, químicas e biológicas do solo, estando as principais causas da degradação relacionadas a desmatamentos, métodos de cultivo, sistemas agrícolas, uso de agroquímicos, etc.

O processo de mineração proporciona uma desfiguração do terreno e uma completa alteração da paisagem. Essas alterações da superfície manifestam-se mais obviamente no aspecto estético, pelos elementos visuais da linha, forma, textura, escala, complexidade e cor que compõe a paisagem (Souza, 1997). Conseqüentemente, causam impactos topográficos, edáficos, vegetativos e hídricos na área de influência direta do empreendimento. A recomposição topográfica das áreas, a drenagem e o plantio de espécies vegetais constituem medidas que minimizam esses impactos.

As estratégias de recuperação de áreas degradadas executadas pelas empresas de mineração, de maneira geral, são baseadas na colocação de um dossel de espécies adaptadas às condições adversas, para a recuperação do substrato degradados (solo) de maneira a auxiliar no desenvolvimento de espécies nativas, que compunham a vegetação local antes do processo de exploração.

O estabelecimento de um dossel vegetal depende da harmonia de uma série de fatores ambientais, sendo que a absorção de nutrientes um dos fatores mais importante neste estabelecimento. Desta forma, qualquer obstáculo que restrinja o crescimento radicular poderá reduzir a absorção dos nutrientes comprometendo o desenvolvimento vegetal. Existem diversos fatores que ocasionam um crescimento deficiente do sistema radicular de espécies vegetais, podendo ser citados alguns: danos causados por insetos e moléstias, deficiências nutricionais, acidez do solo, drenagem insuficiente, baixa taxa de oxigênio, temperatura imprópria do solo, compactação e dilaceramento radicular.

Dentre essas limitações, a compactação do solo atinge, muitas vezes, dimensões sérias, pois ao causar restrições ao crescimento e ao desenvolvimento radicular, acarreta uma série de problemas que afetam as plantas. Os problemas mais comuns de compactação de uma superfície degradada são: aumento da resistência mecânica à penetração radicular, redução da aeração, alteração do fluxo de água e calor, também comprometendo a disponibilidade de água e nutrientes.

Segundo Camargo \& Alleoni (1997) as forças que atuam sobre um solo podem ser classificadas em internas e externas. As forças que resultam do tráfego de animais, veículos e pessoas são consideradas externas e podem promover o aparecimento de camadas compactadas na sub-superfície do solo, sendo considerado uma compactação. As forças que resultam de ciclos como congelamento, umedecimento, desgelo, secamento e contração da massa do solo, provocam o adensamento de camadas sub-superficias e quase sempre está associado à natureza do solo substrato. Os autores relatam que quando o adensamento e a compactação estão associados à unidade de pressão, não faz sentido uma diferenciação.

O cultivo de leguminosas em áreas mineradas como tapete verde auxilia na implantação de espécies nativas. Brussard \& Van faasen (1994) relatam que as dicotiledôneas são mais sensíveis ao impedimento mecânico do que as monocotiledôneas. Canarache (1990) estudou alguns limites de classes de resistência de solos à penetração e graus de limitação ao crescimento, relatando que entre 2,6 MPa e 5,0 $\mathrm{MPa}$, pode ocorrer alguma limitação no crescimento de raízes. Estudos em Latossolos para cultura da soja realizado pela EMBRAPA demostram que valores próximos a 2,5 MPa podem restringir o crescimento radicular.

A compactação de áreas mineradas superficialmente está associada à movimentação de terra e ao intenso tráfego de máquinas pesadas usadas na exploração mineral. Uma medida corretiva da compactação de superfícies é a descompactação da área por meio de subsolagem, que consiste na desagregação do substrato compactado em profundidade. Esta operação é realizada por um conjunto trator-subsolador que demanda altos custos operacionais e energéticos. Mesmo tendo consciência dos valores associados à operação de subsolagem muitos técnicos possuem dificuldades de decidir qual a parte da área a subsolar e as técnicas a serem adotadas.

De acordo com Guerra (1988) o nome "Geoestatística" nasceu para se referir à Aplicação da Teoria das Variáveis Regionalizadas na resolução de problemas de Geologia e Mineração, e foi concebida e idealizada por Matheron (1963) ( in Camargo. 1997) e constitui um critério científico e moderno de interpretação e estudo da maior parte dos fenômenos naturais.

Segundo Vieira (1997) a variabilidade espacial de propriedades do solo vem sendo uma das preocupações de vários pesquisadores, praticamente desde o início do século.

A geoestatística é fundamentada na teoria das variáveis regionalizadas, segundo a qual os valores de uma propriedade do solo estão de alguma forma relacionados à sua distribuição espacial; logo, as observações tomadas a curtas distâncias devem ser semelhantes àquelas tomadas a distâncias maiores. As ferramentas da geoestatística permitem a análise de dependência espacial, como também, a estimativa de dados, para locais não amostrados, através de um estimador sem tendenciosidade. A utilização deste tipo de metodologia 


\section{ACTA \\ AMAZONICA}

DIAGNÓSTICO DE UMA ÁREA COMPACTADA POR ATIVIDADE MINERARIA, NA FLORESTA AMAZÔNICA,EMPREGANDO MÉTODOS GEOESTATÍSTICOS À VARIÁVEL RESISTÊNCIA MECÂNICA À PENETRAÇÃO DO SOLO permite analisar adequadamente dados de experimentos, com possibilidade de obter informações encobertas pela a estatística clássica. Abaixo está elencado alguns conceitos e definições básicas sobre Teoria das Variáveis Regionalizadas, segundo INPE (2002):

- A partir da introdução da geoestatística, surge nas Ciências da Terra um novo tipo de variáveis, denominadas Variáveis Regionalizadas (V.R.);

- Uma Variável Regionalizada : é uma variável distribuída no espaço, usada para representar um fenômeno natural. Ex: o teor de argila contido no solo, pode ser considerado como uma V. R.;

- Os fenômenos naturais, ou as V. Rs., portam sempre consigo um duplo aspecto: um estruturado e um aleatório;

- O aspecto Estruturado : está relacionado com a distribuição global do fenômeno natural. Ex: numa área poluída, existem zonas as quais têm, em média, uma maior quantidade de metal pesado que em outras;

- O aspecto Aleatório : está relacionado com comportamento local do fenômeno natural. Ex: dentro de uma zona, de uma área poluída, o conteúdo de metal pesado flutuar aleatoriamente. Em outras palavras, é impossível prever com exatidão o teor de metal pesado num determinado ponto.

Sendo assim, o presente trabalho teve por objetivo básico diagnosticar de forma espacial a compactação de uma área minerada, através da resistência mecânica à penetração, de maneira a orientar uma futura subsolagem no local, visando posterior revegetação.

\section{MATERIAL E MÉTODOS}

Os trabalhos de campo foram realizados numa área minerada para a exploração de cassiterita junto à Floresta Nacional do Jamari, administrada pelo Instituto Brasileiro do Meio Ambiente e Recursos Minerais Renováveis -IBAMA, situada a $90 \mathrm{~km}$ da cidade de Porto Velho - RO (Figura 1).

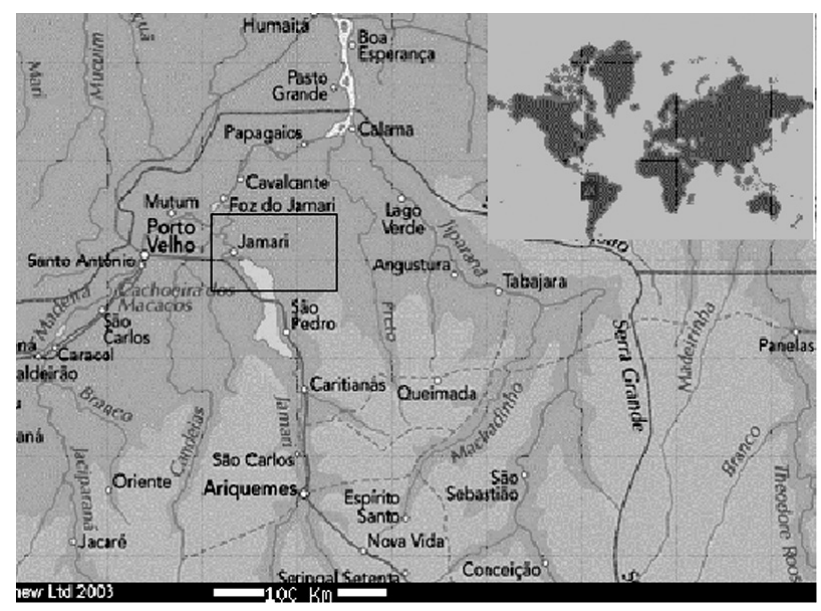

Figura 1 - Localização da FLONA do Jamari/RO, coordenadas UTM, zona 20, 496.721E e 8.987.202N
Para medir os pontos amostrais foi utilizado um nível de engenharia modelo C-41 SOKKIA, com precisão de $2,5 \mathrm{~mm}$ por quilômetro duplo de nivelamento, massa de $900 \mathrm{~g}$ e graduação de $0^{\circ}$ a $360^{\circ}$.

Para determinação da resistência à penetração, na profundidade de 0 a $25 \mathrm{~cm}$, foi utilizado o penetrógrafo tipo Stiboka, produzido pela Eijkelkamp, com penetração máxima de $60 \mathrm{~cm}$ com cone padrão.

Para análise dos dados foram utilizados os seguintes "softweres": Pacote Office, versão 2000 e GS+ "for Windows". O método para o desenvolvimento deste trabalho compreende estudos geoestatísticos para diagnosticar a compactação de uma área minerada.

Os dados foram coletados em pontos eqüidistantes de 20 $\mathrm{m}$, formando uma malha regular disforme com a umidade do solo-substrato variando de $18,04 \%$ a $22,06 \%$, como mostram as Figuras 2 e 3. O total da área levantada pela malha foi de 6,15 ha, em área de piso de lavra (Figura 4).

Os dados concernentes a este trabalho foram analisados através de estudos geoestatíticos referente a variografia, ajuste de modelos e interpolação.

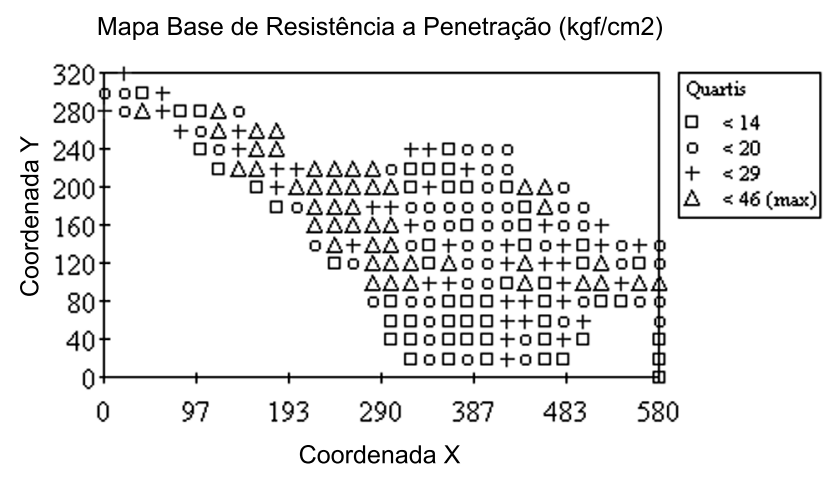

Figura 2 - Mapa base de Resistência à Penetração, mostrando os quartis e suas classes de distribuição

Mapa Base de Resistência a Penetração (kgf/cm2)

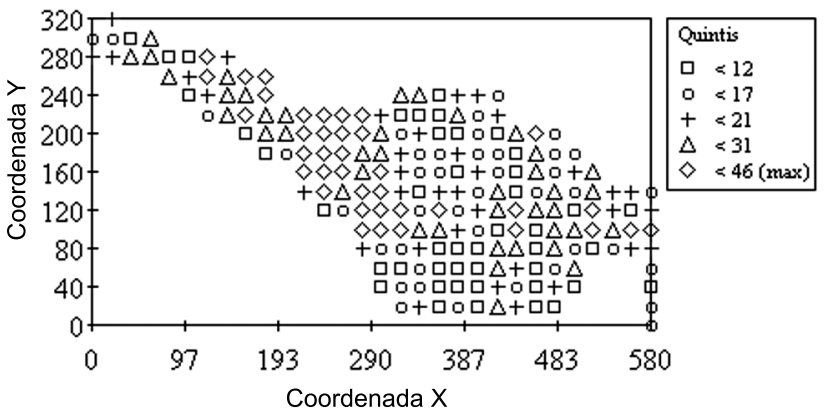

Figura 3 - Mapa base de Resistência à Penetração do solo, com seus valores críticos em azul 


\section{ACTA \\ AMAZONICA}

DIAGNÓSTICO DE UMA ÁREA COMPACTADA POR ATIVIDADE MINERARIA, NA FLORESTA AMAZÔNICA,EMPREGANDO MÉTODOS GEOESTATÍSTICOS À VARIÁVEL RESISTÊNCIA MECÂNICA À PENETRAÇÃO DO SOLO

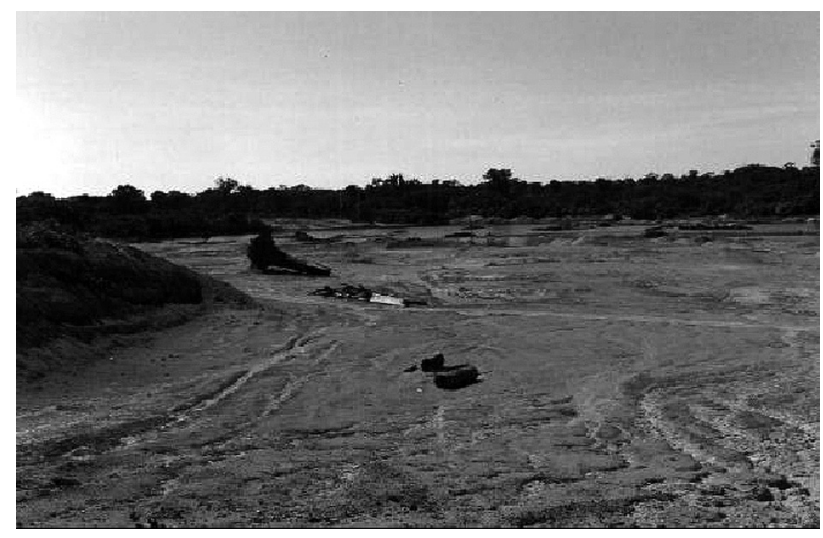

Figura 4 - Local de amostragem (piso de lavra)

\section{RESULTADOS E DISCUSSÃO}

A Tabela 1 apresenta a estatística descritiva da variável resistência à penetração (RP).

Os valores da média e mediana apresentaram-se dentro da faixa de pouca resistência à penetração que é de $1125 \mathrm{kgf.cm}$ ${ }^{2}$ a $25 \mathrm{kgf.cm}^{-2}$ (Tabela 2), ou seja, os valores que se encontraram acima deste intervalo devem ser submetido a algum tipo de operação, no caso a subsolagem. Já o desvio padrão e a variância amostral descreveram como a variável está variando no entorno da média amostral na área. Entretanto, o coeficiente de variação de 49,36\% permite classificar a variável em análise como de média variabilidade de acordo com Warrick \& Nielsen (1980).

A Figura 5 apresenta o histograma de freqüência e da percentagem acumulada. Estas figuras mostraram como a

Tabela 1 - Estatística descritiva da Resistência à Penetração do solo na profundidade de 0 a $25 \mathrm{~cm}$.

\begin{tabular}{ll}
\hline \hline Estatísticas & $\begin{array}{l}\text { Resistência a Penetração } \\
\text { (kgf.cm-2) }\end{array}$ \\
\hline Média & 21,25 \\
Mediana & 20,00 \\
Desvio padrão & 10,48 \\
Variância da amostra & 109,84 \\
Coeficiente de Variação (\%) & 49,36 \\
\hline \hline
\end{tabular}

resistência à penetração foi distribuída. Através da percentagem acumulada foi possível identificar como estavam dispostos os valores da mediana em relação à média amostral. Já que a mediana corresponde ao ponto divisor de 50\% dos dados, quando a freqüência acumulada está disposta em ordem crescente no eixo de y.

No gráfico da percentagem acumulada pode-se identificar o quartil inferior, a mediana e também o quartil superior, de maneira a coligar o local onde estão dispostos e/ou distribuídos no mapa base os valores maiores ou menores da resistência à penetração no solo, como apresentado na Figura 5 .

Em qualquer trabalho estatístico é conveniente estudar qual a distribuição teórica que se ajusta à distribuição observada (distribuição amostral), de modo tal que a partir da distribuição teórica, possam ser feitas inferências em relação à distribuição
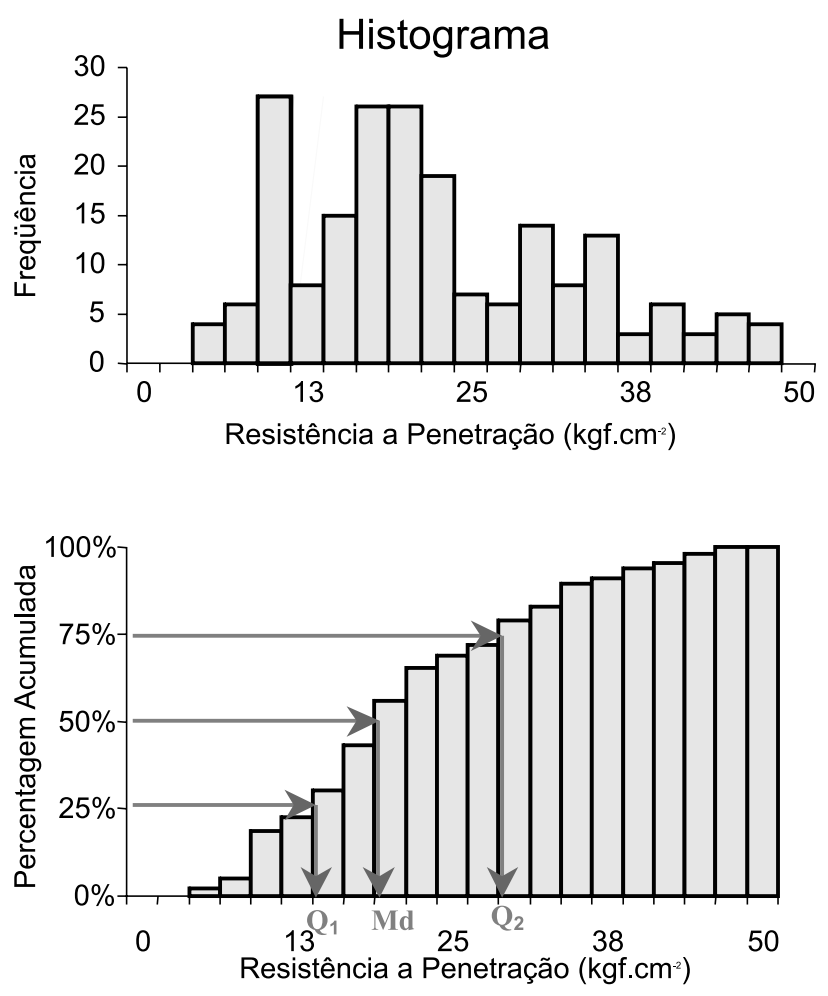

Figura 5 - Histograma de freqüência e percentagem acumulada, respectivamente

Tabela 2 - Limites de classes de resistência de solos à penetração e graus de limitação ao crescimento das raízes (adaptada de CANARACHE, 1990)

\begin{tabular}{lll}
\hline \hline Classes & Limites $(\mathbf{k g f . c m - 2 )}$ & Limitação ao crescimento das raízes \\
\hline Muito baixa & 11 & Sem limitação \\
Baixa & $11-25$ & Pouca limitação \\
Média & $26-50$ & Algumas limitações \\
Alta & $51-100$ & Sérias limitações \\
Muito alta & $101-150$ & Raízes praticamente não crescem \\
Extremamente alta & 150 & Raízes não crescem \\
\hline \hline
\end{tabular}




\section{ACTA \\ AMAZONICA}

DIAGNÓSTICO DE UMA ÁREA COMPACTADA POR ATIVIDADE MINERARIA, NA FLORESTA AMAZÔNICA,EMPREGANDO MÉTODOS GEOESTATÍSTICOS À VARIÁVEL RESISTÊNCIA MECÂNICA À PENETRAÇÃO DO SOLO verdadeira (distribuição populacional). Neste sentido, Guerra (1988) afirma que mesmo existindo várias distribuições teóricas de referência, a experiência mostra que diferentes conjuntos de amostras tendem a se concentrar nas duas mais importantes distribuições teóricas conhecidas, normal e lognormal, contudo em trabalhos onde se aplica a geoestátistica esta consideração não é tão expressiva.

Utilizando-se do software GS+ "for windowsâ", verificouse que a direção de $127^{\circ}$ com a tolerância de deslocamento $22,5^{\circ}$ apresentou uma tendência de estacioraridade da variável. Desta forma, o modelo que apresentou o melhor ajuste, dentre os vários analisados, foi o modelo esférico que tem as seguintes características, $(\mathrm{Co}=35,2)$, patamar $(\mathrm{Co}+\mathrm{C}=130,3)$ e alcance $($ Ao $=128,3 \mathrm{~m})$ para o semivariograma anisotrópico. Este modelo revelou-se bastante similar ao modelo unidirecional que apresentou os seguintes parâmetros: efeito pepita $(\mathrm{Co}=$ $50,2)$, patamar $(\mathrm{Co}+\mathrm{C}=124,3)$ e alcance $(\mathrm{Ao}=173,6 \mathrm{~m})$ (Figura $6)$.

Por meio da Figura 6, pode-se observar o semivariograma anisotrópico para todas as direções sendo visível as variações da resistência à penetração. Na Figura 7 encontram-se os semivariogramas ajustados com seus respectivos modelos, e na Tabela 3 são apresentados os parâmetros de ajustes dos mesmos. Silva (2002) estudando solos em área de plantio de cana, encontrou semivariogramas com características diferentes, com comportamento próximo a um fenômeno de efeito pepita puro.

$O$ alcance de dependência espacial no estudo do semivariograma significa a distância máxima que uma variável está correlacionada espacialmente. Na Figura 7 estão

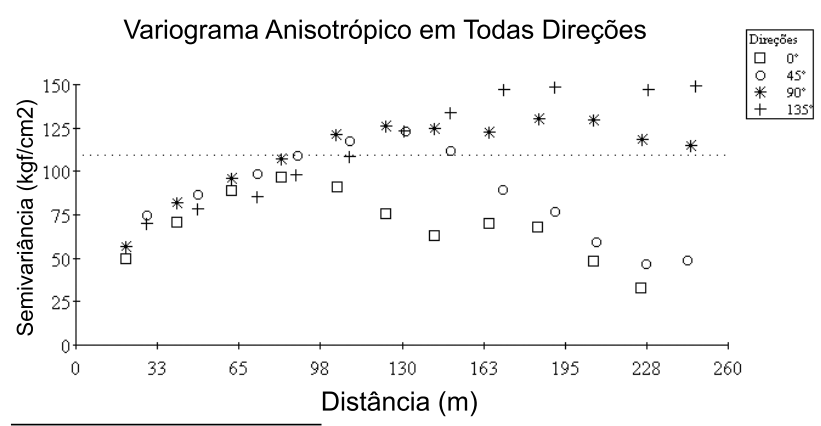

Figura 6 - Semivariograma em todas as direções apresentados o comportamento dos semivariogramas da variável estudada, com seus alcances respectivos Neste limite de dependência espacial (Tabela 3), pode-se proceder à amostragem no campo, minimizando contudo o número das mesmas entre os pontos de resistência mecânica à penetração na área em estudo.

O efeito pepita reflete a variabilidade não explicada ou variações não detectadas pela distância insuficiente da malha de amostragem (Cambardella et al., 1994). Quando expresso como porcentagem da semivariância total (patamar), possibilita melhor comparação entre as variáveis quanto ao grau de dependência espacial (Trangmar et al., 1985).

De acordo com os critérios propostos por Cambardella et al. (1994) semivariogramas com efeito pepita de $<25 \%$, entre $25 \%$ e $75 \%$ e $75 \%$, são considerados de forte, moderada e fraca dependência espacial, respectivamente.
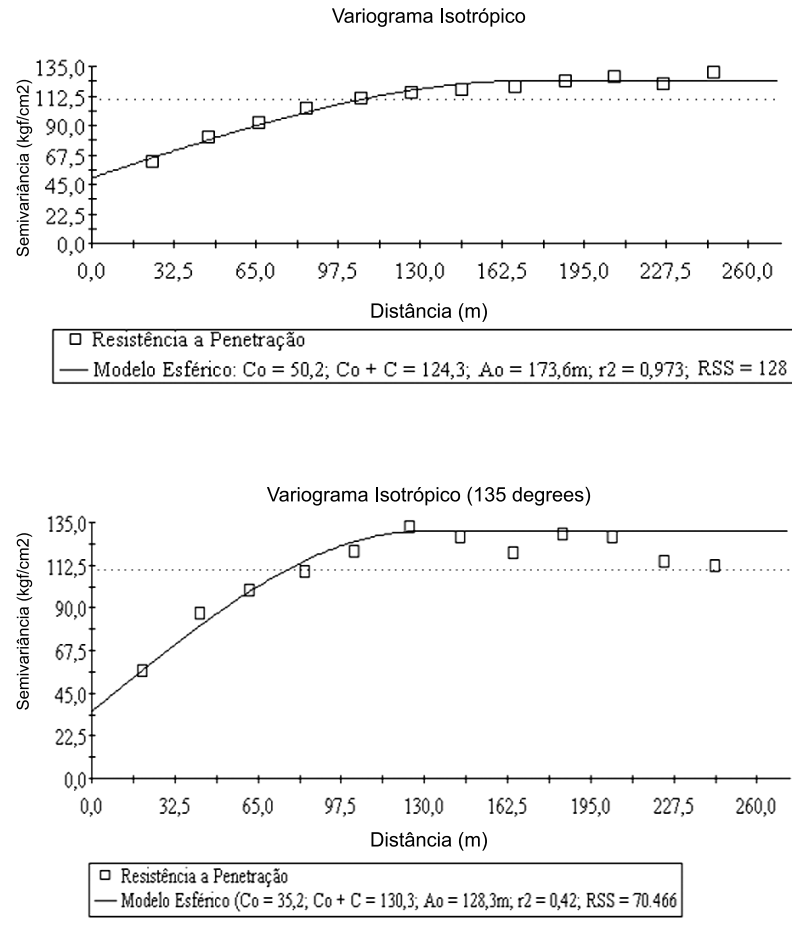

Figura 7 - Semivariograma isotrópico e anisotrópico, respectivamente

Tabela 3 - Parâmetros do modelo esférico ajustado ao semivariograma experimental

\begin{tabular}{|c|c|c|c|c|c|c|c|}
\hline \multicolumn{8}{|c|}{ Resistência a Penetração (kgf.cm-²) } \\
\hline Semivariograma & $C_{0}$ & $C_{0}+C$ & $\mathrm{C} 1$ & Ao $(m)$ & $\varepsilon$ & k & Modelo \\
\hline Isotrópico & 50,2 & 124,3 & 74,1 & 173,6 & 0,677 & 0,596 & Esférico \\
\hline Anisotrópico & 35,2 & 130,3 & 95,1 & 128,3 & 0,370 & 0,729 & Esférico \\
\hline
\end{tabular}

Nota: $\mathrm{C}_{\mathrm{o}}=$ efeito pepita; $\mathrm{C}_{\mathrm{o}}+\mathrm{C}=$ patamar; $\mathrm{C}_{1}=$ variância de dispersão; $\mathrm{Ao}=$ alcance de dependência espacial; $\varepsilon=\frac{C_{0}}{C}-$ e feito pepita relativo de Royle; $\kappa=\frac{C_{0}}{C_{0}+C_{1}}-$ razão de Journel 


\section{ACTA AMAZONICA}

DIAGNÓSTICO DE UMA ÁREA COMPACTADA POR ATIVIDADE MINERARIA, NA FLORESTA AMAZÔNICA,EMPREGANDO MÉTODOS GEOESTATÍSTICOS À VARIÁVEL RESISTÊNCIA MECÂNICA À PENETRAÇÃO DO SOLO
Os valores do efeito pepita que estão contidos na Tabela 3, expressos de maneira relativa $\left(e=\mathrm{C}_{\mathrm{o}} / \mathrm{C}\right)$, indicam que a resistência à penetração apresenta componente aleatória bastante importante, para o semivariograma isotrópico $(0,677)$ e para o anisotrópico $(0,340)$. Já quando expressos em percentagem do patamar $\left\{\left[\mathrm{C}_{\mathrm{o}} /\left(\mathrm{C}_{\mathrm{o}}+\mathrm{C}_{1}\right)\right]^{*} 100\right\}$ indicam que a resistência à penetração de $40 \%$ e 27\%, apresentam moderada dependência espacial, respectivamente, para o semivariograma anisotrópico e isotrópico (Figura 6).

$\mathrm{Na}$ Figura 8 encontram-se os resultados da validação cruzada para semivariograma isotrópico e anisotrópico, respectivamente. Observa-se que muitos pontos foram subestimados e outros superestimados, ou seja, para um valor crítico de resistência a penetração estimada de 25,0 kgf.cm ${ }^{-2}$ tem-se um peso real bem pequeno, porém estes valores não causam nenhum problema, no diagnóstico da área, pois a resistência a penetração assume valores críticos na faixa estimada acima de $25 \mathrm{kgf.cm}-2$, admitindo uma segurança na tomada de decisão para futura subsolagem da área. Desta forma, nota-se que, mesmo com o coeficiente de correlação baixo (isotrópico $r^{2}=0,44$, anisotrópico $r^{2}=0,46$ ) a interpolação não pode ser invalidada.

Nas Figuras 9 a 12 são apresentadas as superfícies interpoladas a partir dos modelos ajustados, considerando o semivariograma isotrópico e anisotrópico, respectivamente. Nestas figuras foi possível visualizar com maior detalhe as áreas críticas e as não críticas no caso acima e abaixo de $25 \mathrm{kgf.cm}$, que deverão ser trabalhadas para homogeneização da superfície na introdução da revegetação. Ainda, nota-se (Figuras 11 e 12) que durante a krigagem foram interpoladas áreas que se afastam dos locais amostrados, porém em ambos os casos, com isotropia e com anisotropia, as áreas críticas são menores.
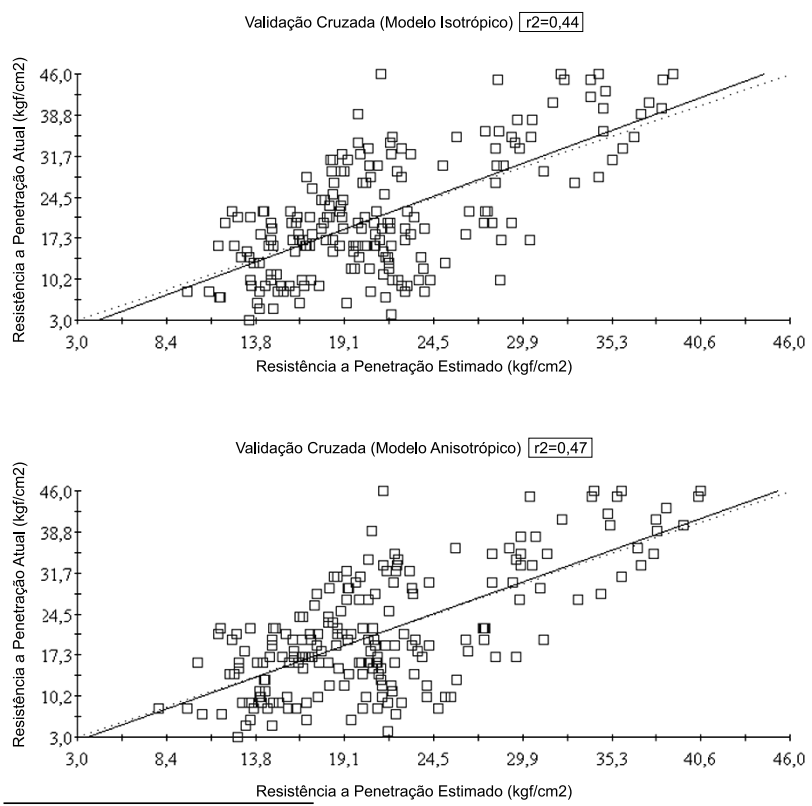

Figura 8 - Validação cruzada para o semivariograma isotrópico e anisotrópico, respectivamente

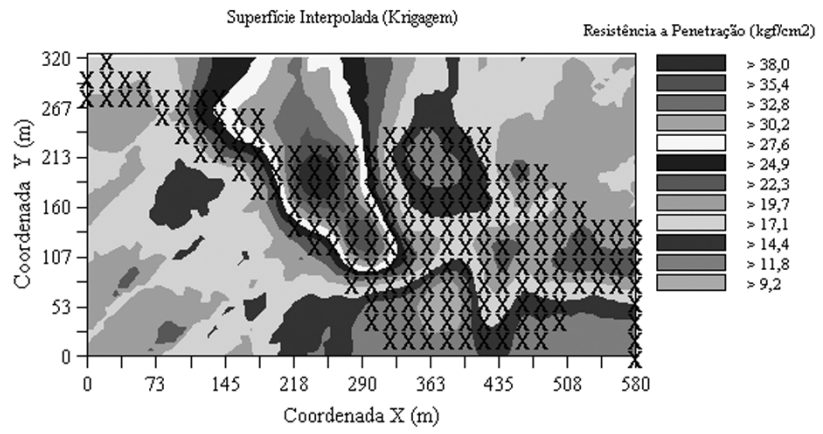

Figura 9 - Superfície interpolada para o semivariograma isotrópico

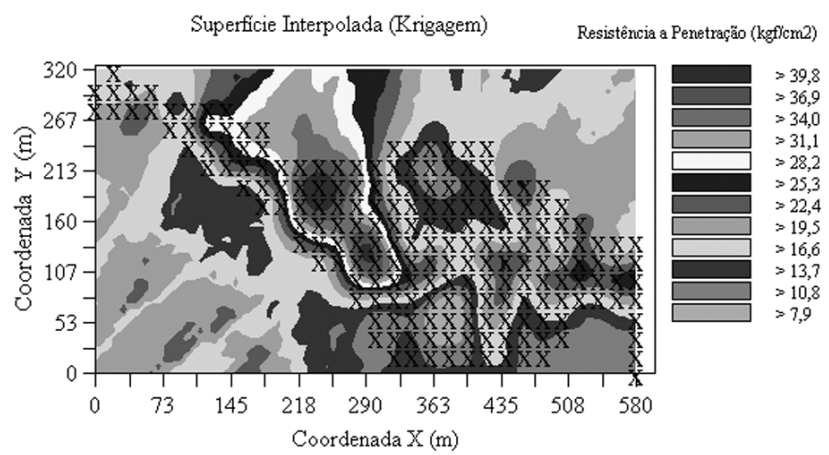

Figura 10 - Superfície interpolada para o semivariograma anisotrópico

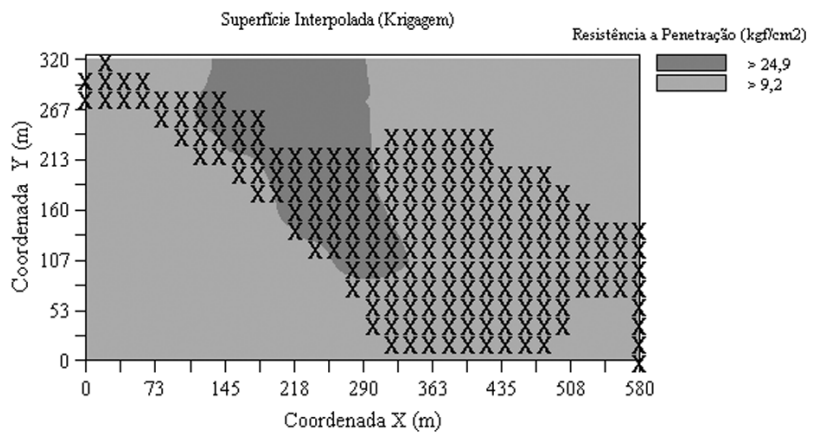

Figura 11 - Superfície interpolada para o semivariograma isotrópico

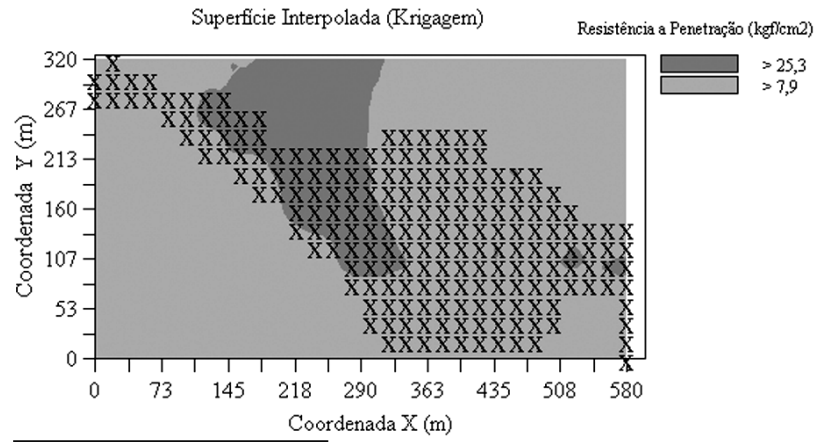

Figura 12 - Superfície interpolada para o semivariograma anisotrópico 


\section{ACTA AMAZONICA}

DIAGNÓSTICO DE UMA ÁREA COMPACTADA POR ATIVIDADE MINERARIA, NA FLORESTA AMAZÔNICA,EMPREGANDO MÉTODOS GEOESTATÍSTICOS À VARIÁVEL RESISTÊNCIA MECÂNICA À PENETRAÇÃO DO SOLO
Analisando a superfície interpolada a partir do modelo anisotrópico (Figura 12) pode-se notar áreas distintas com valor maior que o crítico, mas de uma forma geral, os mapas se mostraram bem parecidos, uma vez que nestes procurou-se uma direção onde havia uma maior homogeneidade da variável estudada, notando-se pouca diferença entre as superfícies. Por esta razão, no caso em estudo, pode-se assumir a interpolação do semivariograma anisotrópico das Figuras 9 e 11, uma vez que as superfícies conseguiram mostrar áreas com resistência à penetração mais compatíveis com a realidade local, ou seja, os altos valores revelaram, com bastante fidelidade, a área com maior tráfego de veículos, entre outros. O total de área estimada acima da faixa de resistência crítica de penetração de raízes, para este estudo, corresponde a 1,68 ha, aproximadamente $27 \%$ da área total, de acordo com a área hachurada correspondente aos valores acima de $25,3 \mathrm{kgf} / \mathrm{cm}^{2}$ na Figura 12.

\section{CONCLUSÕES}

Através do presente trabalho obteve-se as seguintes conclusões:

- O método geoestatístico permite identificar a variabilidade da variável resistência à penetração para a camada de $0 \mathrm{a} 25 \mathrm{~cm}$ do solo/substrato;

- O método de interpolação (krigagem) permite dividir a área estuda em subáreas possibilitando um futuro gerenciamento localizado, de forma a reduzir custos e interferências desnecessárias ao ambiente;

- O método pode ser utilizado em diagnóstico da compactação do solo/substrato prevendo a necessidade de subsolagem em áreas de piso de lavra.

\section{AGRADECIMENTOS}

À Fundação de Amparo à Pesquisa do Estado de São Paulo (FAPESP), pela concessão dos recursos necessários ao desenvolvimento deste trabalho, à CESBRA S/A e ao Instituto Brasileiro do Meio Ambiente e Recursos Minerais Renováveis (IBAMA), pelo apoio logístico, sem os quais este trabalho não poderia ter sido desenvolvido.

\section{BIBLIOGRAFIA CITADA}

Brussard, L.; Van Faassen, H.G. 1984. Effcts of compaction on soil biota and soil biological processes. Soil compaction in croup production. Elsevier, London. p. 215-235.

Camargo, E.C.G. 1997. Desenvolvimento, implementação e teste de procedimentos geoestatísticos (Krigagem) no sistema de processamento de informações georreferenciadas (Spring).
Dissertação de Mestrado, Disponível na Internet. http:// www.dpi.inpe.br/teses/eduardo/. Acesso: 27/01/ de janeiro de 2000.

Camargo, O. A. De, Alleaoni, L. R. F. 1997. Compactação do solo e o desenvolvimento das plantas, Piracicaba, 132pp.

Cambardella, C.A.; Moorman, T.B.; Novak, I.M.; Parkin, T.B.; Karlen. D.L.; Turco, R.F.; Konopka, A.E. 1994. Field-scale variability of soil properties in Central Iowa Soils. Soil Science Society of America Journal, 58:1501-1511.

Canarache, A. 1990. Generalized semi-empirical model estimating soil resistance to penetration. Amsterdam, Soil Till. Res. 16:56-70.

Carpanezzi, A.A; Costa, L.G.S; Kageyama, P.Y.; Castro, C.F.A 1990. Espécies pioneiras para recuperação de áreas degradadas; observações de laboratórios naturais. In: Congresso Florestal Brasileiro, $\sigma^{\circ}$, Campos do Jordão, Anais, p.216-221.

"GS + for windows ${ }^{\circledR} " \mathrm{GS}+$ Geoestatistics for the environmental. Versão 5.3.1, Gamma Design Software, 19892002.

Guerra, P.A.G. 1988. Geoestatística operacional . Ministério das Minas e Energia, Departamento de Produção Mineral. Brasília. 145p.

INPE. Divisão de Processamento de Imagens. Aspectos Básicos de Geoprocessamento. <http://www.dpi.inpe.br/cursos/ ser301/aula3.ppt>, 21/03/2002.

Lal, R; Stewart, B.A. 1992. Need for land restoration. Advanced in Soil Science, 17:.1-9.

Silva, G. 2002. Métodos auxiliares para diagnóstico da necessidade de subsolagem de solos agrícola. Dissertação de Mestrado. FEAGRI, UNICAMP, Campinas-SP. 123p.

Souza, J.A. 1997. Avaliação das estratégias de recuperação de áreas degradadas pela mineração de bauxita em Poços de Caldas (MG). Tese de Doutorado. Universidade Federal de Lavras. Lavras. 104p

Trangmar, B.B.; Yost, R.S.; Uehara, G. 1985. Application of geostatistics to spatial studies of soil properties. Advances in soil science, 38:45-94.

Vieira, S.R. 1997. Geoestatística em estudos de variabilidade espacial. Instituto Agronômico de Campinas. Campinas.

Warrick, A. W.; Nielsen, D. R. 1980. Spatial variability of soil physical properties in the field. In: Hilled, D. (ed.) Application of soil physic, Academic Press: New York, 13: 139-4.

RECEBIDO EM 28/11/2003
ACEITO EM 06/12/2005 
